\title{
GENTAMICIN SULPHATE PERMEATION THROUGH PORCINE INTESTINAL EPITHELIAL CELL MONOLAYER
}

\author{
Béla Gyetvai, Ákos Jerzsele, Erzsébet PÁszTi-Gere, Gábor NAGY and Péter GÁlfi \\ Department of Pharmacology and Toxicology, Faculty of Veterinary Science, \\ Szent István University, István u. 2, H-1078 Budapest, Hungary
}

(Received 23 May 2014; accepted 29 October 2014)

\begin{abstract}
Gentamicin is an aminoglycoside antibiotic widely used in combination with dimethyl sulphoxide (DMSO) in topical drug formulations. It is not known, however, whether DMSO can enhance the permeation of gentamicin through biological membranes, leading to oto- and nephrotoxic side effects. A simple and reliable high-performance liquid chromatographic (HPLC) method was applied for the quantitative determination of gentamicin collected from the apical and basolateral compartments of the porcine intestinal epithelial cell line IPEC-J2 cell monolayer using fluorometric derivatisation of the analyte with fluorenylmethyloxycarbonyl chloride (FMOC) prior to chromatographic run in the presence and absence of $1 \%$ DMSO. The lack of change in transepithelial electrical resistance (TER) demonstrated that gentamicin and 1\% DMSO did not affect IPEC-J2 cell monolayer integrity via the disruption of cell membranes. Chromatographic data also ascertained that gentamicin penetration across the cell monolayer even in the presence of $1 \%$ DMSO was negligible at $6 \mathrm{~h}$ after the beginning of apical gentamicin administration. This study further indicates that the addition of this organic solvent does not increase the incidence of toxic effects related to gentamicin permeation.
\end{abstract}

Key words: Gentamicin, DMSO, IPEC-J2, permeation

Gentamicin is one of the most potent aminoglycoside antibiotics commonly used in veterinary and human medicine for the treatment of infections caused mainly by Gram-negative aerobic bacteria and staphylococci. Under certain physiological and pathological conditions, however, its systemic use is ototoxic and nephrotoxic, and thus it cannot be administered to young or dehydrated animals and to patients with renal insufficiency. In the companion animal practice, gentamicin is often administered topically in the form of suspensions, creams, ointments or ear drops, if the tympanic membrane is still intact (Parravicini et al., 1982; Oghan et al., 2011). Direct contact with the inner ear at high local concentrations can result in severe irreversible ototoxic effects (El Bakri et al., 1998). A higher incidence of ototoxicity was reported in animals than hu-

*Corresponding author; E-mail: gyetvai.bela@alpha-vet.hu; Phone: 0036 (1) 478-4170; Fax: 0036 (1) 478-4172 
mans (Morizono, 1988) following topical administration of gentamicin as an ear drop.

Gentamicin can also cause systemic toxic effects if it is absorbed through biological membranes such as the tympanic membrane, the conjunctiva or the intestinal epithelium. Although the oral bioavailability of gentamicin is usually less than $3 \%$ in healthy animals, oral uptake might also be a toxicological issue if topical preparations containing the surfactant dimethyl sulphoxide (DMSO) are consumed and ingested by animals, although even DMSO concentrations as high as $10 \%$ did not have an effect on the permeability of the apical membrane or tight junctional complexes in Caco2/TC7 cells (Da Violante et al., 2002). Therefore, it is important to determine if DMSO supplementation increases the transport of gentamicin across cell layers, which would increase the potential toxic effects of this aminoglycoside.

Structurally, gentamicin is a 4,6-disubstituted aminocyclitol composed of the core aminocyclitol moiety 2-deoxystreptamine (2-DOS), which is complemented with purpurosamine and garosamine aminosugars at positions $\mathrm{C}-4$ and $\mathrm{C}$ 6 , respectively (Fig. 1). In its therapeutic form, gentamicin comprises a complex of gentamicin $\mathrm{C}_{1}, \mathrm{C}_{1 \mathrm{a}}$ and $\mathrm{C}_{2}$, which differ only in the degree of methylation of the C-6' position of the sugar attached at C-4 of 2-DOS (Testa and Tilley, 1976). The other component of gentamicin is $\mathrm{C}_{2 \mathrm{a}}$, which is a 6'-C epimer of C2 (Seidl and Nerad, 1988). Several papers on high-performance liquid chromatographic (HPLC) methods (Isoherranen et al., 2000; Al-Amoud et al., 2002) with fluorometric detection have been published for the quantitative determination of the gentamicin complex consisting of closely related compounds such as $\mathrm{C}_{1}, \mathrm{C}_{1 \mathrm{a}}, \mathrm{C}_{2}$ and $\mathrm{C}_{2 \mathrm{a}}$. Among derivatisation techniques, o-phthalaldehyde (OPA) and fluorenylmethyloxycarbonyl chloride (FMOC) are frequently applied to detect gentamicin in complex biological matrices. In our model system, the IPEC-J2 cell line was grown on microporous membranes to ensure spontaneous cell differentiation, which is a prerequisite for studying the transport processes through polarised epithelial monolayer present between the apical and basolateral compartments (Tremblay et al., 2006; Cencic and Langerholc, 2010; Langerholc et al., 2011).

The transcellular permeation of gentamicin is practically not possible in view of its relatively high molecular weight and highly polar and hydrophilic nature (Rama Prasad et al., 2003). Paracellular permeation across tight junctions, however, might occur (Madara, 1989; González-Mariscal et al., 2003), and DMSO can facilitate this process by modulating protein assembly in tight junctions. At higher concentrations, DMSO is known to disrupt lipid structures in epithelia (Gordeliy et al., 1998; Simons, 2008) and thus it can facilitate the penetration of certain substances. It was previously described that labrasol, a nonionic surfactant, enhanced the oral bioavailability of gentamicin (Hu et al., 2001) probably via tight junction opening mechanisms. 


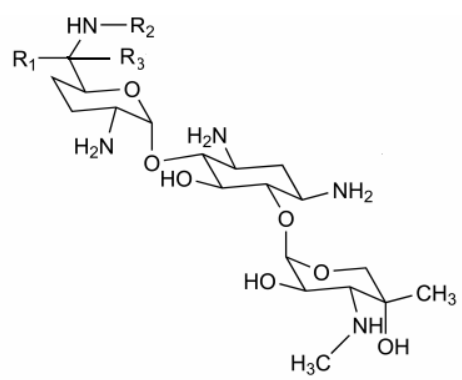

\begin{tabular}{lll|}
\hline Gentamicin $\mathrm{C}_{1}$ & $\mathrm{R}_{1}=\mathrm{R}_{2}=\mathrm{CH}_{3}$ & $\mathrm{R}_{3}=\mathrm{H}$ \\
Gentamicin $\mathrm{C}_{1 \mathrm{a}}$ & $\mathrm{R}_{1}=\mathrm{R}_{2}=\mathrm{R}_{3}=\mathrm{H}$ & \\
Gentamicin $\mathrm{C}_{2 \mathrm{a}}$ & $\mathrm{R}_{1}=\mathrm{R}_{2}=\mathrm{H}$ & $\mathrm{R}_{3}=\mathrm{CH}_{3}$ \\
Gentamicin $\mathrm{C}_{2}$ & $\mathrm{R}_{1}=\mathrm{CH}_{3}$ & $\mathrm{R}_{2}=\mathrm{R}_{3}=\mathrm{H}$ \\
\hline
\end{tabular}

Fig. 1. Chemical structure of gentamicin complex: $\mathrm{C}_{1}, \mathrm{C}_{1 \mathrm{a}}, \mathrm{C}_{2}$ and $\mathrm{C}_{2 \mathrm{a}}$

The aim of this study was to determine the permeation of gentamicin across a monolayer of the porcine intestinal epithelial cell line, IPEC-J2 in the presence and absence of $1 \%$ DMSO using HPLC with fluorescence detection based on derivatisation of the analyte with fluorenylmethyloxycarbonyl chloride (FMOC). The results can contribute to an in-depth prediction of the topical or oral absorption of gentamicin in the presence of DMSO.

\section{Materials and methods}

The IPEC-J2 cell line used in this study was derived from jejunal epithelia of a neonatal piglet and was a kind gift from Dr. Jody Gookin, North Carolina State University, USA. It is a non-transformed cell line that in some respects mimics in vivo conditions when cultured on membrane inserts. Cells form a differentiated monolayer and are attached to each other via tight junctions apically. The high transepithelial electrical resistance (TER) of IPEC-J2 monolayers grown on Transwell polyester filters coated with rat tail collagen shows the functional integrity of a continuous, uninterrupted cell layer. Only monolayers with a TER value of at least $8,000 \mathrm{Ohm} / \mathrm{cm}^{2}$ were used as a model system to study the cellular barrier permeability. The cells were maintained in a complete medium containing 1:1 mixture of Dulbecco's Modified Eagle's Medium and Ham's F-12 Nutrient Mixture (DMEM/F12) supplemented with 5\% FBS, $5 \mu \mathrm{g} / \mathrm{ml}$ insulin, $5 \mu \mathrm{g} / \mathrm{ml}$ transferrin, $5 \mathrm{ng} / \mathrm{ml}$ selenium, $5 \mathrm{ng} / \mathrm{ml}$ epidermal growth factor and $1 \%$ penicillin-streptomycin (all from Fisher Scientific, USA). Cell cultures were tested by PCR and were found to be free of mycoplasma contamination. IPEC-J2 cells were seeded at a density of $1.5 \times 10^{5}$ per well on six-well plates with Transwell polyester membrane inserts (pore size: $0.4 \mu \mathrm{m}$; surface area: $4.67 \mathrm{~cm}^{2}$; 
Sigma, Germany) coated with rat tail collagen (Sigma) in a $1.5-\mathrm{ml}$ apical and 2.6- $\mathrm{ml}$ basolateral volume. Cells were allowed to adhere for $24 \mathrm{~h}$ before being washed and re-fed every other day until confluence. They were grown at $37^{\circ} \mathrm{C}$ in a humidified atmosphere of $5 \% \mathrm{CO}_{2}$ for three weeks before the experiments. Three replicas were used for each treatment.

Prior to the treatments, IPEC-J2 cells were washed twice with plain medium (complete medium without FBS and antibiotics). Six-well inserts were treated apically with $1 \mathrm{mg} / \mathrm{ml}$ of gentamicin sulphate (Sigma) and with gentamicin sulphate supplemented with 1\% DMSO (Sigma) dissolved in plain medium. The basolateral compartments of the Transwell inserts were filled with plain medium. Treatment lasted for 1 and $6 \mathrm{~h}$, and TER was measured at different time points (before treatment and $6 \mathrm{~h}$ after treatment). One $\mathrm{ml}$ from each apical and basolateral medium was collected at different time points $(0 \mathrm{~h}, 1 \mathrm{~h}, 6 \mathrm{~h})$, diluted in PBS and the amount of gentamicin present in the apical and basolateral compartments was determined by HPLC.

For the determination of gentamicin concentration in the apical and basolateral compartments, a Merck LaChrome Elite HPLC system with a Spherisorb ODS-2 $(5 \mu \mathrm{m}$ pore size, $250 \times 4.6 \mathrm{~mm})$ column was used with fluorescent detection and an eluent consisting of $85 \%$ acetonitrile and $15 \%$ ultra-pure water. The temperature of the column and the autosampler was $25^{\circ} \mathrm{C}$ and $20^{\circ} \mathrm{C}$, respectively. The excitation and emission wavelengths of fluorescent detection were $260 \mathrm{~nm}$ and $315 \mathrm{~nm}$, respectively. Flow rate was $1 \mathrm{ml} / \mathrm{min}$, injection volume was $25 \mu \mathrm{l}$ and the running time was $34 \mathrm{~min}$. Preparation of standards $(2,1,0.5,0.2$ and $0.1 \mu \mathrm{g} / \mathrm{ml}$ ) was achieved with the dilution of $50 \mathrm{mg} / \mathrm{ml}$ gentamicin sulphate (Sigma) standard with ultra-pure water and a diluent consisting of $50 \%$ acetonitrile (Prolabo, Thailand) and 50\% borate buffer (Merck, Germany). The peak area and the concentration showed a good linear relationship, while the concentration of gentamicin was between $0.1 \mu \mathrm{g} / \mathrm{ml}$ and $2 \mu \mathrm{g} / \mathrm{ml}, \mathrm{r}^{2}=0.9997$. DMEM/F12 medium and DMEM/F12 supplemented with $1 \%$ DMSO were used as blank. Derivatisation was achieved with $10 \mathrm{mM}$ fluorenylmethyloxycarbonyl chloride (Merck) solution for $15 \mathrm{~min}$. The reaction was stopped with $0.1 \mathrm{M}$ glycine solution (Merck). The method was validated, the limit of detection (LOD) was $0.19 \mathrm{ng} / \mathrm{ml}$ and the limit of quantification (LOQ) was $0.63 \mathrm{ng} / \mathrm{ml}$, indicating the high sensitivity of the method.

An unpaired, two-sample Student's $t$-test was used for the statistical analysis.

\section{Results and discussion}

Previous studies have shown that IPEC-J2 cells are able to differentiate with a parallel expression of tight junction proteins and increasing TER values (Schierack et al., 2006), forming a cell monolayer that acts as a barrier against 
polar substances of high molecular weight. Claudins and E-cadherin have been considered as key integral protein regulators responsible for the maintenance of electrical resistance and paracellular integrity (Oliveira and Morgado-Diaz, 2007). Previous findings indicate that certain solvents, like the surfactant labrasol, can disrupt tight junction integrity, and thus enhance the penetration of gentamicin across membranes (Hu et al., 2001). This phenomenon was not observed when gentamicin was supplemented with another solvent, $1 \%$ DMSO.

To assess the effect of the substances on the integrity of the cell monolayer, TER was determined before and after the treatment. TER was measured and was consistently above $8,000 \mathrm{Ohm} / \mathrm{cm}^{2}$ before treatment and $6 \mathrm{~h}$ after treatment. Figure 2 shows the observed TER values of gentamicin and gentamicin $+1 \%$ DMSO treated IPEC-J 2 cell cultures before and after $6 \mathrm{~h}$ of treatment.

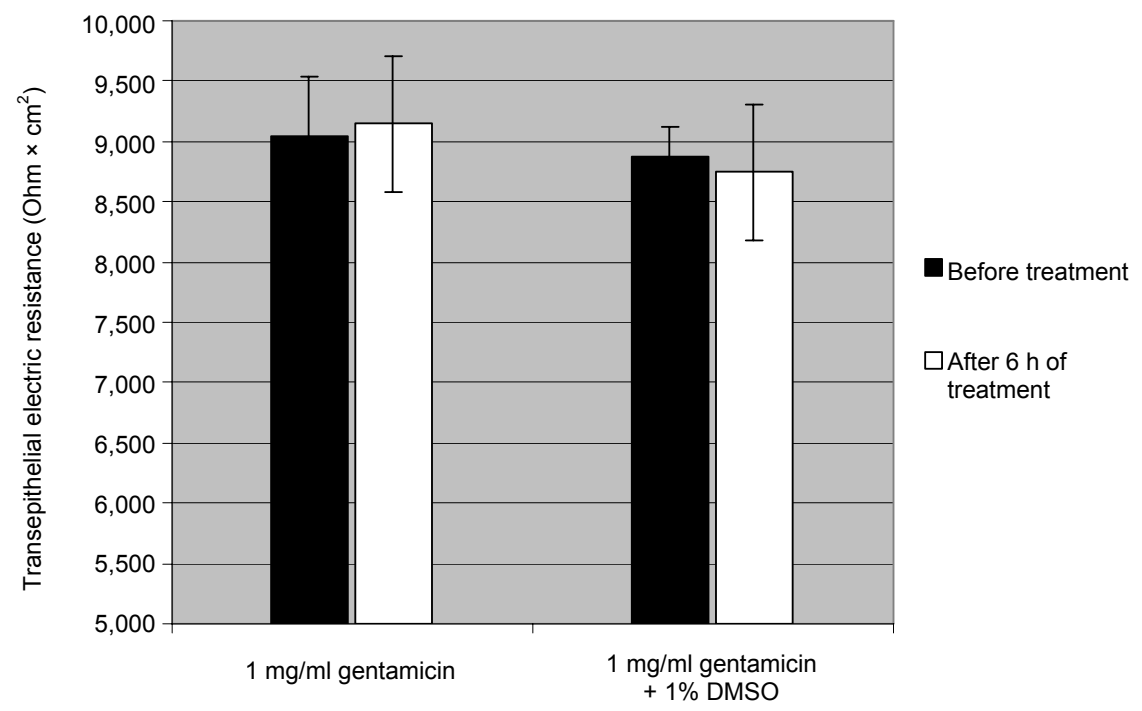

Fig. 2. Transepithelial electric resistance (TER) values before treatment and after 6 hours of treatment with $1 \mathrm{mg} / \mathrm{ml}$ gentamicin and $1 \mathrm{mg} / \mathrm{ml}$ gentamicin supplemented with $1 \%$ DMSO (mean $\pm \mathrm{SD}$ )

There was no significant difference $(\mathrm{P}>0.05)$ between TERs before the treatment and $6 \mathrm{~h}$ after treatment with gentamicin or gentamicin in $1 \% \mathrm{DMSO}$, thus it is assumed that cell integrity was damaged neither by $1 \mathrm{mg} / \mathrm{ml}$ gentamicin nor by gentamicin supplemented with $1 \%$ DMSO. TER values show that neither gentamicin nor gentamicin supplemented with 1\% DMSO alters tight junction formation and paracellular integrity. It was previously described (Konari et al., 1995) that DMSO can even induce the expression of tight junction proteins and thus increase TER values. At the low concentration of DMSO used in this study, this phenomenon was not observed. 
Table 1 shows the transport of gentamicin in the presence and absence of $1 \%$ DMSO in the insert without cells and across the IPEC-J2 cell monolayer. In wells without cells, an almost total equilibrium in gentamicin concentration was achieved after $6 \mathrm{~h}$ between apical and basolateral compartments. Addition of $1 \%$ DMSO did not alter gentamicin transport significantly $(\mathrm{P}>0.05)$. The membrane insert served as a time-dependent barrier as it delayed the equilibration of gentamicin concentrations between the two compartments. In wells with cell monolayer, no gentamicin was detected in the basolateral compartment either in wells treated with gentamicin or in wells treated with gentamicin $+1 \% \mathrm{DMSO}$, $1 \mathrm{~h}$ after treatment, and the total gentamicin content was detected in the apical region (Fig. 3). Six h after treatment, a very low amount of gentamicin was measured in the basolateral compartment. No significant difference $(\mathrm{P}>0.05)$ was observed in gentamicin levels in wells treated with gentamicin alone or in combination with $1 \%$ DMSO. Thus, gentamicin shows poor transcellular and paracellular permeation across a cell monolayer in vitro. DMSO added in $1 \%$ concentration did not enhance the permeation of the aminoglycoside through cell monolayers. Therefore, it can be assumed that $1 \%$ DMSO does not significantly alter gentamicin penetration across monolayer biological membranes in vitro. The results of TER and HPLC measurements prove that DMSO in 1\% concentration does not alter paracellular integrity and thus gentamicin permeation in IPEC-J2 cells.

Table 1

Concentrations of gentamicin (\%) in apical and basolateral compartments in wells containing IPEC-J2 cell monolayer and in control wells contaning no cells

\begin{tabular}{|c|c|c|c|c|c|}
\hline \multirow[b]{2}{*}{ Treatment } & \multirow[b]{2}{*}{$\begin{array}{c}\text { Time } \\
\mathrm{h}\end{array}$} & \multicolumn{2}{|c|}{ Insert without cells } & \multicolumn{2}{|c|}{ Cell monolayer } \\
\hline & & $\begin{array}{c}\text { Apical } \\
\text { compartment } \\
(\%)\end{array}$ & $\begin{array}{c}\text { Basolateral } \\
\text { compartment } \\
(\%)\end{array}$ & $\begin{array}{c}\text { Apical } \\
\text { compartment } \\
(\%)\end{array}$ & $\begin{array}{c}\text { Basolateral } \\
\text { compartment } \\
(\%)\end{array}$ \\
\hline \multirow[t]{3}{*}{ Gentamicin } & 0 & $99.85 \pm 0.24$ & $0.00 \pm 0.29$ & $98.36 \pm 0.90$ & $0.15 \pm 0.12$ \\
\hline & 1 & $72.38 \pm 1.07^{*}$ & $26.47 \pm 1.52^{*}$ & $99.13 \pm 0.85$ & $0.05 \pm 0.23$ \\
\hline & 6 & $52.13 \pm 0.53^{*}$ & $46.81 \pm 0.32^{*}$ & $99.94 \pm 0.01$ & $1.12 \pm 0.81$ \\
\hline \multirow[t]{3}{*}{ Gentamicin in $1 \%$ DMSO } & 0 & $99.65 \pm 0.62$ & $0.15 \pm 0.29$ & $99.54 \pm 0.21$ & $0.41 \pm 0.08$ \\
\hline & 1 & $72.67 \pm 1.15^{*}$ & $27.12 \pm 1.29^{*}$ & $98.56 \pm 0.91$ & $0.11 \pm 0.05$ \\
\hline & 6 & $54.45 \pm 1.23^{*}$ & $44.98 \pm 1.31^{*}$ & $99.93 \pm 0.02$ & $0.05 \pm 0.01$ \\
\hline
\end{tabular}

Explanations: $100 \%$ represents initial apical gentamicin concentration. Significant differences $\left({ }^{*} \mathrm{P}<\right.$ $0.05)$ in gentamicin permeation were found between initial value at $\mathrm{t}=0 \mathrm{~h}$ and $\mathrm{t}=1 \mathrm{~h}$ or $\mathrm{t}=6 \mathrm{~h}$ when insert was not covered with cell layer. Data are shown as means \pm SEM $(n=6)$

Ear drops containing gentamicin are often used in human and veterinary medicine for the treatment of external otitis since staphylococci and Pseudomonas aeruginosa are frequently present in such conditions. Because of a potential 
irreversible ototoxic effect (Matz et al., 2004), gentamicin-containing products cannot be used in cases with a perforated tympanic membrane (Rosenfeld et al., 2006). Although the present studies were conducted on monolayer IPEC-J2 cells, our results suggest that gentamicin alone or supplemented with $1 \%$ DMSO cannot penetrate through the intact tympanic membrane into the inner ear. The tympanic membrane is coated with a striated multilayered epithelium, thus offering further protection from the potential ototoxic effect of gentamicin. The tight barrier due to IPEC-J2 cells grown in a monolayer and linked by tight junction proteins is less complex than the multilayered tympanic membrane, and therefore our approach is over-predictive. Furthermore, our data show that the addition of the organic solvent DMSO did not alter the transport of gentamicin through an intestinal epithelial monolayer, hence it might not enhance the oral absorption of gentamicin if ingested accidentally. Whether our in vitro results can be extrapolated to the in vivo situation remains to be investigated.

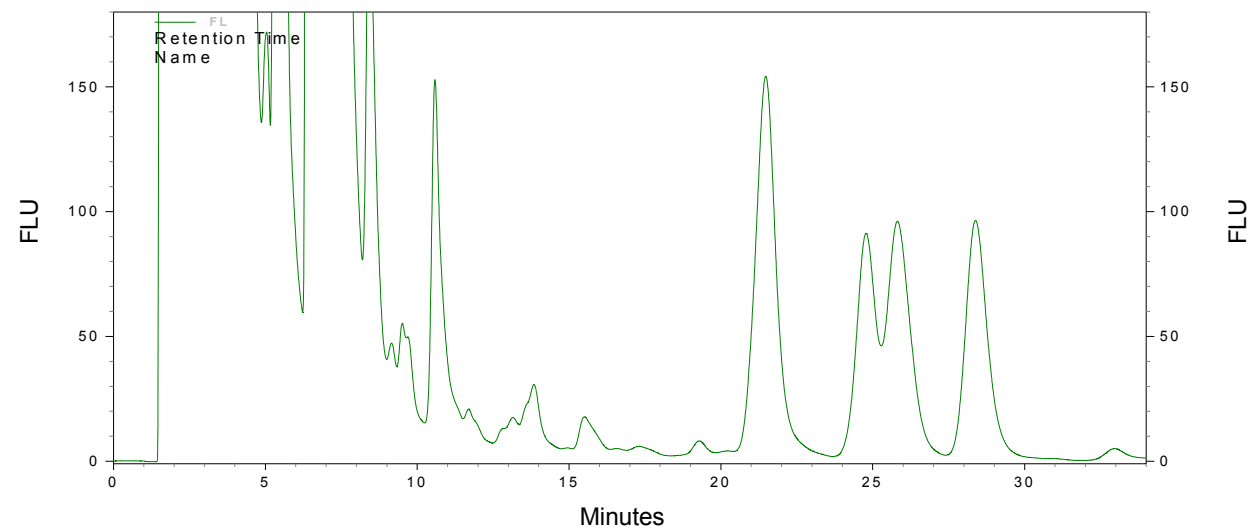

Fig. 3. Representative chromatogram of gentamicin complex collected from the apical compartment of the IPEC-J2 cell monolayer. The order of elution with mobile phase $(85 \% \mathrm{ACN}$,

$15 \% \mathrm{UPW}$ ) was gentamicin $\mathrm{C}_{1}\left(\mathrm{t}_{\mathrm{ret}}=21.89 \mathrm{~min}\right)$, gentamicin $\mathrm{C}_{1 \mathrm{a}}\left(\mathrm{t}_{\mathrm{ret}}=24.7 \mathrm{~min}\right)$, gentamicin $\mathrm{C}_{2 \mathrm{a}}$ $\left(\mathrm{t}_{\mathrm{ret}}=25.67 \mathrm{~min}\right)$ and gentamicin $\mathrm{C}_{2}\left(\mathrm{t}_{\mathrm{ret}}=28.42 \mathrm{~min}\right)$. The fluorescence detection wavelengths were $260 \mathrm{~nm}$ (excitation $\lambda$ ) and $315 \mathrm{~nm}$ (emission $\lambda$ ). The flow rate was adjusted to $1 \mathrm{ml} / \mathrm{min}$

In conclusion, gentamicin showed poor paracellular permeation across the IPEC-J2 monolayer. Addition of 1\% DMSO did not disrupt paracellular integrity and did not alter the transport of gentamicin. Our results indicate that the inclusion of DMSO in this low concentration as part of the drug formulation does not promote the oral absorption of gentamicin and it does not enhance the incidence of ototoxic effects caused by gentamicin in ear drop application. In the future, gentamicin can be used for detecting epithelial barrier dysfunction during LPSinduced bacterial infection or acute oxidative stress when chromatographic separation and quantitative fluorometric determination of gentamicin collected from basolateral compartment of IPEC-J2 cell monolayer is performed. 


\section{Acknowledgements}

We are indebted to Dr. Adam Csordas, Division of Medical Biochemistry, Biocenter, Innsbruck Medical University, Innsbruck, Austria for critical reading of the manuscript. The research was supported by the Hungarian Scientific Research Fund (OTKA, grant number: 100701).

\section{References}

Al-Amoud, A. I., Clark, B. J. and Chrystyn, H. (2002): Determination of gentamicin in urine samples after inhalation by reversed-phase high-performance liquid chromatography using precolumn derivatisation with o-phthalaldehyde. J. Chromatogr. B 769, 89-95.

Cencic, A. and Langerholc, T. (2010): Functional cell models of the gut and their applications in food microbiology - A review. Int. J. Food Microbiol. 141, 4-14.

Da Violante, G., Zerrouk, N., Richard, I., Provot, G., Chaumeil, J. C. and Arnaud, P. (2002): Evaluation of the cytotoxicity effect of dimethyl sulfoxide (DMSO) on Caco2/TC7 colon tumor cell cultures. Biol. Pharm. Bull. 25, 1600-1603.

El Bakri, F., Pallett, A., Smith, A. G. and Duncombe, A. S. (1998): Ototoxicity induced by oncedaily gentamicin. Lancet 351, 1407-1408.

González-Mariscal, L., Betanzos, A., Nava, P. and Jaramillo, B. E. (2003): Tight junction proteins. Prog. Biophys. Mol. Biol. 81, 1-44.

Gordeliy, V. I., Kiselev, M. A., Lesieur, P., Pole, A. V. and Teixeira, J. (1998): Lipid membrane structure and interactions in dimethyl sulfoxide/water mixtures. Biophys. J. 75, 2343-2351.

Hu, Z., Tawa, R., Konishi, T., Shibata, N. and Takada, K. (2001): A novel emulsifier, labrasol, enhances gastrointestinal absorption of gentamicin by inhibiting transporter. Life Sci. 69, 2899-2910.

Isoherranen, N., Lavy, E. and Soback, S. (2000): Pharmacokinetics of gentamicin $C_{1}, C_{1 a}$ and $C_{2}$ in beagles after a single intravenous dose. Antimicrob. Agents Ch. 44, 1443-1447.

Konari, K., Sawada, N., Zhong, Y., Isomura, H., Nakagawa, T. and Mori, M. (1995): Development of the blood-retinal barrier in vitro: Formation of tight junctions as revealed by occludin and ZO-1 correlates with the barrier function of chick retinal pigment epithelial cells. Exp. Eye Res. 61, 99-108.

Langerholc, T., Maragkoudakis, P. A., Wollgast, J., Gradisnik, L. and Cencic, A. (2011): Novel and established intestinal cell line models - an indispensable tool in food science and nutrition. Trends Food Sci. Tech. 22, S11-S20.

Madara, J. L. (1989): Loosening tight junctions. Lessons from the intestine. J. Clin. Invest. 83, 1089-1094.

Matz, G., Rybak, L., Roland, P. S., Hannley, M., Friedman, R., Manolidis, S., Stewart, M. G., Weber, P. and Owens, F. (2004): Ototoxicity of ototopical antibiotic drops in humans. Otolaryng. Head Neck Surg. 130, 79-82.

Morizono, T. (1988): Ototopical agents: ototoxicity in animal models. Ann. Otol. Rhinol. Laryngol. 97, 28-30.

Oghan, F., Apuhan, T. and Y1lmaz, F. (2011): Ototoxicity caused by topical administration of gentamicin versus tobramycin in rabbits. Int. J. Pediatr. Otorhi. 75, 915-918.

Oliveira, S. S. and Morgado-Diaz, J. A. (2007): Claudins: multifunctional players in epithelial tight junctions and their role in cancer. Cell. Mol. Life Sci. 64, 17-28.

Parravicini, L., Arpini, A., Bamonte, F., Marzanatti, M. and Ongini, E. (1982): Comparative ototoxicity of amikacin, gentamicin, netilmicin, and tobramycin in guinea pigs. Toxicol. Appl. Pharm. 65, 222-230. 
Rama Prasad, Y. V., Eaimtrakarn, S., Ishida, M., Kusawake, Y., Tawa, R., Yoshikawa, Y., Shibata, N. and Takada, K. (2003): Evaluation of oral formulations of gentamicin containing labrasol in beagle dogs. Int. J. Pharm. 268, 13-21.

Rosenfeld, R. M., Brown, L., Cannon, C. R., Dolor, R. J., Ganiats, T. J., Hannley, M., Kokemueller, P., Marcy, S. M., Roland, P. S., Shiffman, R. N., Stinnett, S. S. and Witsell, D. L. (2006): Clinical practice guideline: Acute otitis externa. Otolaryng. Head Neck Surg. 134, 4-23.

Schierack, P., Nordhoff, M., Pollmann, M., Weyrauch, K. D., Amasheh, S., Lodemann, U., Jores, J., Tachu, B., Kleta, S., Blikslager, A., Tedin, K. and Wieler, L. H. (2006): Characterization of a porcine intestinal epithelial cell line for in vitro studies of microbial pathogenesis in swine. Histochemistry 125, 293-305.

Seidl, G. and Nerad, H. P. (1988): Gentamicin C: Separation of $\mathrm{C}_{1}, \mathrm{C}_{1 \mathrm{a}}, \mathrm{C}_{2}, \mathrm{C}_{2 \mathrm{a}}$ and $\mathrm{C}_{2 \mathrm{~b}}$ components by HPLC using isocratic ion-exchange chromatography and post-column derivatisation. Chromatographia 25, 169-171.

Simons, E. J. (2008): Chemical penetration enhancers and in situ forming reservoirs for transtympanic drug delivery: Progress toward improved treatment of otitis media. Doctoral Thesis. Massachusetts Institute of Technology, Cambridge, USA.

Testa, R. T. and Tilley, B. C. (1976): Biotransformation, a new approach to aminoglycoside biosynthesis: II. Gentamicin. J. Antibiot. 29, 140-146.

Tremblay, E., Auclair, J., Delvin, E., Levy, E., Menard, D., Pshezhetsky, A. V., Rivard, N., Seidman, E. G., Sinnett, D., Vachon, P. H. and Beaulieu, J. F. (2006): Gene expression profiles of normal proliferating and differentiating human intestinal epithelial cells: A comparison with the Caco-2 cell model. J. Cell. Biochem. 99, 1175-1186. 